\title{
Archeology of tattoos and other brands in the contemporary body: the mystical stigma to body art
}

\begin{abstract}
This study aims to characterize the phenomena of tattoos, piercings and other brands and signals produced along the body length, so expressive among teenagers and young contemporaries, to then relate them to other cultural events involving the body, located in the religious field and the other in the aesthetic: the mystical stigmata and body art, respectively. The three events (tattoos and piercings, body art and mystical stigmata), although in its own way and according to the temporal and ideological circumstances that have defined, show the plastic character of the meat, as a guarantee for the subject of virtual triumph over natural.
\end{abstract}

Keywords: body, tatoos, piercings, body art, mystical stigmata
Volume 4 Issue 5 - 2019

\author{
Ario Borges Nunes Junior \\ Doctor, department of Social Psychology, University of São \\ Paulo, Brazil
}

Correspondence: Ario Borges Nunes Junior, Doctor,

Psychoanalysis Office, Brazil,Tel II 55350I79,

Email abnjaos@gmail.com

Received: August 26, 2019 | Published: October 17, 2019

\section{Introduction}

In contemporary times, they have drawn the attention of clinicians and researchers to self-harm, especially in the bodies of young people. ${ }^{1}$ Such lesions can be grouped in two main areas: one on social acceptance and other directed by critics of the group of belonging of the subject in question. Tattoos and piercings are housed in the first category, while the cuts, mechanically caused and accompanied by the passive contemplation of bloodshed on the part of its author, cause, immediately, a rejection by the community. Especially for the latter cases, we turn the attention of psychoanalysts, psychologists and doctors, since such phenomena require interventions in an attempt to preserve the health not only mental but also physical. It is clear that self-inflicted marks present in the eyes of scholars as a result of psychic phenomena of highly complex logic.

\section{Tattoos and other interventions on the body of significant contemporary expression}

\section{Historical considerations about the practice of tattoos}

Applications on body length are present in all civilizations and were constituted as ritual involving certain liturgical practices throughout human history. It has news inscriptions on the body since the dawn of humanity. The practice of tattooing is not suited to Jewish ideology: in the biblical book of Leviticus (19:28), is a direct reference to prohibition of incisions in the body. Dating back two thousand years before the Christian era, in ancient Egypt, brands were found in the abdominal region of Amunet mummy (2160-1994 BC); the marks on the mummy's body were interpreted as allusions to fertility rituals (cf.superabril.com.br). In Greco-Roman antiquity, the etymology of the words nomeavam entries in the human body came from stig root, which means prick. For these civilizations, over the centuries, the diffusion of the practice of tattooing has been facilitated by sea shipment, the usual leading to the most distant points of the globe. The culture of the tattoo was a ship's culture, spread by sailors, who also exercised the craft of tattoo artists. The practice of tattooing exerted a strong presence in closed institutions such as prisons and barracks. Confinement seems to encourage incisions in the body surface itself, so that such surface serves to subject it to record elements of their personal history lived in a different context that made up their original references. Thus, one might think that the main dynamic that mobilizes the production of marks on the body itself is driven by the desire to avoid the risk of separating from the story itself, More recently, at the height of the Enlightenment mentality, with the expansionist fury of Europeans, they are recognized as tattooed bodies of the peoples of Polynesia, which was recorded in the logbook of the expedition chief, James Cook, in 1780, even this record, is the first word that gave rise to the term tattoo: tatau, of Tahitian origin, whose meaning is related to the act of marking the skin with sharp objects and pigments. ${ }^{2}$ The technique involves injecting a pigment in the skin is formed so that a stain on the skin surface. Throughout the history of the West, the incidence and spread of such practices were present, more or less ideological expression.

In the contemporary era, for example, the practice of tattooing has a significant expression bodies. From the 1970s, the twentieth century began to spread various rebel movements to social conventions, such as the punks, for example. In these contexts, tattoos and other productions on the body portray the search for a personal uniqueness, amid pageantry parade of options to try to anchor a recognizable identity himself. ${ }^{3}$

\section{Identification and mapping the flesh}

From an anthropological point of view, one can think of the practice of printing physical marks on the skin as a possibility to bring own personal history inscribed in the body. It touches different types of cultural experiences: religious rituals, the identification of strategies and belonging to a group, the definition of a social, aesthetic appeal of ornamentation, the need for camouflage, among others. While message to groups associated with the power, the tattoos can express a transgression of attitude to standards imposed by the dominant social ideology. The tattoo stimulates the body's exposure by forcing the expansion of the limits of tolerance and acceptance of the group in relation to dealing with it. Increasingly, it is acceptable reprocess it at own will, at whim, according to the most eccentric refinements. 
In contemporary times, swarming'maneiras to treat the body so that it reaches the maximum performance: functional and aesthetic. minimalist techniques and diets of physical education, involving stretching and strength, guarantee an efficient body functioning, integrated with nature conservation requirements; garments that shape the body so that it is obtained an increasingly optimized performance as finitude resistance insignia; reformulation of body mass by surgery and other ortopráxicas techniques. All this suggests the body as a display screen for signs marked it thus opens the possibility to model it, set it up, dress it. Entries in the body can also act as a way to sanctify everything, to offer you a second skin,

A perspective of more metaphysical trends may place the marks of tattoos and other skin inscriptions on the aesthetic level. Body surface, in this sense, acts as a screen just like the one in which the painter will enter the strokes of your brush, or the stone block within which the sculptor find, after much chopping, the ideal way to fix his work in the objective world. The body taken as a work allows redefinition by two parts: the plasticity, i.e. the transformation of an uninterrupted and, as a result of this, the cultural construction of the body as the message to be decrypted. The body, in these conditions, updates the function of absolute Other for the subject. It establishes, as well, a pattern of relationships between him and his body as otherness

The marketing aspect settles comfortably: there is something for everyone. Ideology related to tattoos and other body inscriptions developed in such contexts. Always, for them, there is a character, but of choice, at least for membership, ritualistic. The subject recognizes in the concreteness of body marks a material sign of their evanescent existence. It is recognized as adept to an ideology, in some similar company. The sign on the skin makes it a protective surface symbolically against the uncertainty of the world; the body confers an affiliation via a rite of passage: moving body moves itself. ${ }^{3}$ All this seems authenticated by the shedding of blood and the perception of pain. Some psychoanalytic inspiration of research emphasizes the logic of this IDs in interest in the practice of tattooing. At the same time, membership mark to a particular group, expressed by the ritual inscription insignia on the body and the symbolic meaning attributed to its visionary content, and its differentiation as a single subject, since the marks are printed under certain circumstances they say relate exclusively to that subject at that particular time frame. ${ }^{4}$ Thus, the tattoos can be thought of as signs of contradiction of experience in relation to their own bodies, at once so familiar and yet so strange, so intimate and so community.

It is always an acknowledgment of identity that the subject seeks to make use of body intervention techniques of feature that became known by the general body modification expression. It offers a multitude of images of bodies that can support any identity. Images recorded on the skin surface and injuries voluntarily produced by objects confronted with the natural body give voice to a veiled message, cryptic, often guided by a logic not immediately recognizable by the subject. ${ }^{5}$ The skin folds entered into a second garment. Also, it is at stake is also the feeling. The search sharp contrasts skilled in the flesh in the form of pain and anxiety.

\section{Blood and pain}

There are other instances, however, where the tattoo figure as a dash down. In such cases, the very will of the subject does not act as motivation for the execution of the procedure. The mark of a fault or emblem of an ethnic group give the subject a precarious social status, as a prisoner or slave. Have been studied the marks made in confined bodies subject to such conditions as, for example, in Nazi death camps. Registrations, usually numerical, are carried out without the knowledge of the subject. The body is medium and there tattooed and perpetuated brand works materially as a sociopolitical warning sign, first the descendants of deportees, then society as a whole. These marks printed on their bodies make them living witnesses of a historical reality that should not be repeated. ${ }^{6}$ The wide range of representations associated with body marks will, step by step, referring to the amazing fantasy universe, staged along the axis victim-pain. The pursuit of pain perception, the acts defined as self-mutilation, that is, deliberately injuring the body, has drawn the attention of researchers. In the Diagnostic and Statistical Manual of mental disorders, is defined not suicidal self-injury category, the essential diagnostic feature concerns the "repeated behavior oneself to inflict superficial injuries, though painful, to the surface of your body." The subject recognizes that such acts are aimed at "reducing negative emotions such as stress, anxiety and self-censorship, and / or resolve an interpersonal difficulty; in some cases the injury is designed as a deserved-punishment".?

The application materials character, which probably produced blood and pain to be formed, functions as a point of just eternal virtuality of thought, as witness the body in its natural, dies, but continues to insinuate that its symbolic expression can achieve the summit. The inherent resistance flesh consistency can be overcome by forming a loop, i.e. a "libido investment' ${ }^{8}$ The elasticity of libido allows the establishment with various types of objects: with a specific circumstance of life, a person, a group or an ideology. The pain that follows the production of the brand aims to enrich the act with the imaginary consistency. Mass membership of people in relation to tattoos and other body inscriptions like the piercings, the scarring can be explained by the fact that the painful manipulation techniques of the body itself are related to a transcendent purpose, namely, to overcome the pain physics, or at least not give him credit, "however, the pain is not valued, not redemptrix or initiation, not even a limit - is indifferent, no one owns it". ${ }^{3}$ However, the perception of pain, watered by the blood flow, acts as imaginary witness the consistency of the scene that takes place in such circumstances. Several research support in the establishment of relationships between clinical facts and traditional psychoanalytic concepts such as death drive, masochism etc. Giving the skin to be drilled and then filled with a dye involves the perception of taking the body as an inscription surface and communication, idea so well put by psychoanalytic thinking that goes beyond its primarily natural value and assumes the vehicle condition of a message about the history of the subject. The skin surface boundary confirms its role, the transition between inside and outside. ${ }^{1}$ Such impressions are given immediately, not being fully supported by the symbolic operations making it necessary to use the imaginary consistency, ie, the specific brand dug in meat and blood testified. ${ }^{9}$

\section{The body as limit}

David Le Breton, ${ }^{3}$ to analyze the phenomena related to tattoos and piercings, take the body from the perspective of a sort of snapshot of the subject picture. Highlights the temporal aspect involved in autoinduzidas physical metamorphoses. However, the succession can be endless, from a conceptual point of view, but runs out against

\footnotetext{
${ }^{1}$ Moreira JO, Teixeira LC, Nicholas RF. Body Application: tattoos, body piercings and the light scarification of psychoanalysis. Rev Latinoam Psicopatol Founded. 2010;13(4)
} 
an eminently physical perspective, natural. Although ultimately, the body continues to be an insurmountable limit. The body interventions will expand in scale: tattooing, piercing, transsexualism, producing anomalies in certain regions of the body, the performances. ${ }^{10}$ The issue of meat plasticity takes on the height of his radicalism in some artistic forms grouped under the name of body art, inhabiting a territory between the fine arts and the performing arts. The French artist Orlan transforms into body art in carnal art, as she called it, surgical interventions for the remodeling of the body, filmed and broadcast video. Under these conditions, the body is located beyond the pain. "In the operating performance, the artist demystifies the surgery, since she herself decides to turn his body as subject of the action, in a position to serve the Science of mastery to question the science itself". ${ }^{11}$ The idea of permanence of the organic substance gives rise to a totally transmuted body, of which the voice, word only support left unchanged.

Marina Abramovic, exponent of contemporary art, born in Bulgaria and resident in Italy, revolutionized the idea of performance putting to the test the body, its limits and its expressive power; the artist proposes a body without limits. The confrontation with the pain is controllable, which want to prove extreme situations staged by some actors of body art. ${ }^{12}$ The work embodied in the artist's body, and for that he needs your double that in each performance, is assumed by the public, which, in turn, is involved in a collective experience that questions the ordinary nature of existence and everyday behavior rules; It is as if the artist offered his hand to the viewer "and the success of the operation depends on how and how much the viewer is willing to accept it" ${ }^{13}$ It is essential that the public cooperate with the artist, as this needs to be confirmed in their identity. With the "work", it establishes a relation of otherness and it is from this experience that envisions for the artist the possibility of self-consciousness, according to Merleau-Ponty (1994), the work is part of the body itself and this carnality warrants to be a prehuman existence. The body modifications want to prove that the body is malleable; never reaches a definitive form, the body is always to be done in an unfinished and imperfect form. ${ }^{3}$

\section{Mystic stigmas: archeology of contemporary body inscriptions}

The liturgy of the body that has marked and wounded with sharp objects, blades and pins has a long history. The most striking body insignia of Christian imagery is the possibility of the appearance of the wounds of the Passion of Christ in the body of a believer. Until the thirteenth century, the desire to identify with Christ by some mystics and mystical was updated in physical conformation by the impact of a sharp object. The classical hagiografia lists some examples, and B1 Cristina Spoleto $(\dagger 1458)$ or Elisabeth Herkenrode $(\dagger 1275) .{ }^{14}$ With St. Francis of Assisi (1182-1226), comes in the psychological dimension: the desire to identify with Christ is able to trigger the physical process, body, no longer needed the mechanical action of the sharp object. In the Baroque era, for example, a number of Christian mystics describe the abuse that subjected their bodies for reasons of guilt and atonement. For example, on the Capuchin mystic Maria Maddalena Martinengo (1687-1736), of Brescia, Italy, beatified in 1900, it was written that "thorns dipped in the body, particularly the head" and also by a doctor who examined the body: "it is admirable that the needles in the body have not given or inflammation or ulcers or gangrene". ${ }^{15}$

The phenomenon of mystical stigma began to be approached with greater theological precision with the figure of the saint of Assisi. The reflections on this category of mystical phenomenon appeared inspired by the hagiographic records on their person, in which there were stories about the incidence of these marks on his body at the end of his life caused by the ecstatic vision of the winged seraphim. The stigmata, besides the pain and the blood produced that attest to its consistency, are not subject to classical temporal logic, that is, the historical period in which he lived the saint. Theologically, all that Christ lived in its historical dimension, still present in its transcendent dimension, which in due course, may again manifest in specific activities, re-entering at any time in the historical dimension again, via the body of the mystic. ${ }^{16}$ There is also the effect on the day of the week in the case relates to the appearance of the wounds on Thursdays and his subsequent disappearance on Fridays. In the production of mystical stigmata, the way it discusses, by which the subject relates to his own body, that is, as he employs to imaginatively support their identity, according to a sense of enjoyment economy. You can use the body as unquestionable testimony.

The question of the origin of mystical stigmata is quite complex. Sustains the religious discourse that its occurrence is accompanied by altered state of consciousness-ecstasy. Desire is performed only by metaphysical forces: the wounds conform without any forceful stimulus that could break the surface of the skin, however, can not completely rule out the possibility that the injury would be produced mechanically by the subject in an altered state consciousness so he could not later remember your act, giving it an enigmatic origin. In addition to the own history of tattooing and other body marks, they developed also other manifestations in specific contexts such as religious, in which the ascetic practices and sacrifice entailed in bringing the body to the various forms of exhaustion. The classic mystical stigmata so familiar to Christian mysticism has an obvious kinship. Its alleged transcendental origin, however, puts them on a level above. The brand, accordingly, runs contrary to the logic of the tattoos of concentration camps or slave, i.e, it has a prerogative value election. Another approach point between tattoos and Mystic stigmas relates to coloring pigments used in the first case and the loose blood in the second. In the narratives about the dynamics of stigmatization, membership must be guaranteed with a mark on the body. Purely symbolic resources are not enough to fix some elements of the chain of words, then the body has to make that temping. ${ }^{17-20}$

\section{Final considerations}

The interest in tattoos and other interventions in the body, such as piercings, scarification that the intensified and expanded remarkably in recent decades dialogues with other phenomena that had incidence in historical times of various ideologies, but have similar characteristics and common structures. It should be taken into account, from the 1960s and 1970s, the simultaneity of the cutting edge of body art and that incalculable increase in the interest of people, especially young people and adolescents to practice painful incisions in the body. distancing themselves further in time, you can make use of the mystical stigmatization phenomenon, defined within the Christian mystic. This phenomenon has several elements in common with the radical contemporary interventions in the body, although it is defined in a different ideological and aesthetic context. In summary, the mystical stigmata may be seized according to three perspectives of a general nature, which also are present in these mass contemporary phenomena in relation to adolescents and young people: the inscription as material presence of a virtual reality, such as signal belonging to a group and to support an identity recognized; the value of printed bodily sensation as pain and blood; and the instantaneous character of each image, i.e, 
Stigmatization and contemporary body marks always appeal to the plasticity of the flesh, which suggests and tries to immortalize the triumph of language. The power of desire can trivialize the pain and exempt from the natural rules. That seems to be what the guy wants to witness when it presents for himself and the other a calculatedly martyred body.

\section{Acknowledgments}

None.

\section{Conflicts of interest}

Author decalres that there is no conflict of interest.

\section{References}

1. Diogo Frasquilho Guerreiro, Daniel Sampaio. Self-injurious behavior in adolescents: a literature review focused on research in Portuguese. Revista Portuguesa de Saúde Pública. 2013;31(2):213-222.

2. Jeha S. A history of tattooing in Brazil: the nineteenth century to the 1970s. São Paulo: Veneta; 2019.

3. Le Breton D. Farewell to the body: anthropology and society. Campinas PaPiRus; 2007.

4. Azevedo AF. Body Directions: metaphor and interdiscourse. 2014. p. 321-335.

5. Pires BF. The support body as art: piercing, implants, scarification, tattoo. São Paulo: Editora Senac; 2005.

6. Ramos CMA. Nazi tattoos: registration or injuries in the human body? Sao Paulo: Perspective; 2006.

7. Diagnostic and statistical manual of mental disorders. DSM-V.
8. Soler C. What does tie? São Paulo: Listen; 2016.

9. Juliana Falcão Barbosa de, Daniela Scheinkman, Isalena Santos, et al. The body pain: self-mutilation, and Masochism drive. Estilos da Clinica. 2016;21(2):497-515.

10. Corbin - Courtine - Vigarello History of the Body. 3. Changes in the look. The twentieth century. Petropolis: Voices; 2008.

11. Grecco MG. Orlan: the meat that makes verb. 43. Option Lacanian Journal bbrasileira International Psychoanalytical. São Paulo; 2005. p. 108-111.

12. Marina Abramovic. The cleaner. Firenze: Palazzo Strozzi; 2019.

13. Vergine L. Il corpo come linguaggio: la "Body Art" and storie simili.

14. Thurston H. Les phénomès physiques du mysticism. Editions Gallimard. 1961.

15. Leite J. Daily Santos II. 4th ed. Braga: Editorial AO; 2003.

16. Artola AM. Introducción. Santa Gema Galgani La gloria de la Cruz: Autobiography - Spiritual Diary - Letters - Éxtasis - Other writings. Madrid: cristianos authors Library; 2002. p. 11-44.

17. The CW BYNUM ressurrection of the body in Western Christianity, 200-1336. New York: Columbis University Press; 1995.

18. Le Breton D. Anthropology and modern body. Petropolis: Voices; 2011.

19. Freitas Simone Aparecida, Oliveira Linda Marques de, Souza Selma, et al. Phenomenology of Perception. São Paulo: Martins Fontes; 1994.

20. Jacqueline de Oliveira Moreira, Leônia Cavalcante Teixeira, Roseane de Freitas Nicolau. Body inscriptions: tattoos, piercing and scraping in the light of psychoanalysis. Revista Latinoamericana de Psicopatologia Fundamental. 2010;13(4). 